\title{
Percepções de estagiários sobre as suas práticas de avaliação das aprendizagens
}

\section{Perceptions of trainees on their practices of evaluation of learning}

\author{
Carlos Alberto Ferreira*
}

\begin{abstract}
RESUMO
A avaliação das aprendizagens tem de constituir, sobretudo, uma prática realizada para promover as aprendizagens nos alunos. Deste modo, foi nossa intenção aceder às percepções dos estagiários do $1^{\circ}$ ciclo do ensino básico da Universidade de Trás-os-Montes e Alto Douro sobre as suas práticas de avaliação das aprendizagens. Para isso foi administrado um questionário de questões abertas à totalidade dos estagiários no fim do estágio do ano letivo de 2016/2017. Da análise de conteúdo feita às respostas escritas, foi possível perceber que, tendo eles uma percepção da avaliação das aprendizagens numa lógica formativa, afirmaram ter realizado práticas de avaliação formativa pontuais e contínuas, o que lhes possibilitou elaborar um diagnóstico dos processos de aprendizagem dos alunos, dar-lhes feedback e regular esses processos.
\end{abstract}

Palavras-chave: Percepções. Estagiários. Práticas de avaliação das aprendizagens.

\begin{abstract}
The evaluation of learning has to be, above all, a practice carried out to promote learning in students. Thus, it was our intention to access the perceptions of the trainees of the first cycle of basic education of the University of Trás-os-Montes and Alto Douro on their practices of evaluation of learning during their internship. For this, we passed a questionnaire of open questions to the all the trainees at the end of the 2016/2017 school year internship. From the content analysis of the written answers, it was

* Universidade de Trás-os-Montes e Alto Douro.Vila Real, Portugal. E-mail: caferreira@ utad.pt. https://orcid.org/0000-0003-1752-1796.
\end{abstract}


possible to perceive that, having a perception of evaluation the learning in a formative logic, they affirmed to have carried out punctual and continuous formative evaluation practices. This enabled them to elaborate a diagnosis of the learning processes of students in their internship school classes, giving feedback and regulating them.

Keywords: Perceptions. Trainees. Learning evaluation practices.

\section{Introdução}

A avaliação da aprendizagem deve ser entendida, sobretudo, como um processo realizado para promover a aprendizagem nos alunos. Para isso, tem de assumir uma dimensão formativa e, dessa forma, estar integrado no processo de ensino e de aprendizagem. Sendo essa avaliação contínua, é orientada para a formação de juízos avaliativos que identifiquem as aprendizagens feitas, as dificuldades dos alunos e os fatores que as originaram. Com esta dimensão formativa, a prática da avaliação tem de implicar o aluno e deve concretizar-se pela recolha de informações sobre os processos de aprendizagem e pela sua análise em função de critérios delimitados para as diferentes tarefas em que os alunos se envolvem. Assim é possível elaborar um diagnóstico dos processos de aprendizagem e intervir atempadamente com estratégias pedagógicas que sejam adequadas às diferentes necessidades detetadas nos alunos.

Tendo sido recentemente publicado um novo normativo que regulamenta a avaliação das aprendizagens no ensino básico português, no qual é valorizada a dimensão formativa da avaliação para estimular a aprendizagem e o sucesso escolar nos alunos, pretendemos aceder às percepções dos estagiários do $1^{\circ}$ ciclo do ensino básico da Universidade de Trás-os-Montes e Alto Douro sobre as suas práticas de avaliação das aprendizagens no estágio desse nível de ensino realizado no ano letivo de 2016/2017. Daí o presente texto visar apresentar o estudo realizado, bem como os resultados através dele obtidos.

Assim iniciamos este texto com uma abordagem teórica sobre a avaliação na e para a aprendizagem dos alunos, seguindo-se algumas ideias teóricas sobre a prática de uma avaliação que promove a aprendizagem nos alunos. No ponto seguinte, destacamos a forma como a avaliação formativa se encontra descrita no atual normativo que regulamenta a avaliação das aprendizagens no ensino básico português. Descrevemos, em seguida, a metodologia de investigação usada no estudo, com a identificação do problema e dos objetivos de investigação, dos participantes no estudo e, ainda, dos procedimentos de recolha e de análise de 
dados. Por fim, apresentamos e refletimos sobre os resultados obtidos com a investigação à luz do enquadramento teórico elaborado.

\section{A avaliação na e para a aprendizagem}

Estamos já distantes de uma concepção de avaliação da aprendizagem como uma prática realizada externamente ao processo de ensino e de aprendizagem e que tem, unicamente, por finalidade a medição de resultados de aprendizagem dos alunos e a sua hierarquização numa escala formalmente adotada, para a tomada de decisões de aprovação ou de reprovação.

O aparecimento do conceito de avaliação formativa no artigo de Scriven intitulado The methodology of evaluation, publicado em 1967, e a influência do construtivismo trouxeram uma mudança de paradigma na avaliação das aprendizagens, que, assim, viu diversificar os seus âmbitos, as suas finalidades e funções (FERREIRA, 2007; NEVES; FERREIRA, 2015). Com a diversificação dessas finalidades e funções da avaliação,

passa-se a falar de avaliação somativa quando nos referimos aos processos que procuram responder às exigências sociais da educação, como hierarquizar, seleccionar, certificar, e de avaliação formativa quando se procura desenvolver processos cujo principal intuito é o de contribuir para a aprendizagem (SANTOS et al., 2010, p. 5).

É, sobretudo, pela intenção e pelas funções que lhes estão subjacentes que a avaliação formativa se distingue das outras modalidades de avaliação, mais do que o momento que é realizada e os instrumentos em que nela são usados (SANTOS, 2016). Por isso, Santos (2016, p. 640) afirma que "existem duas funções essenciais da avaliação: avaliar para ajudar a aprender e avaliar para sintetizar a aprendizagem. No primeiro caso, estamos perante um propósito formativo, no segundo, num registo somativo."

Com uma dimensão formativa de influência cognitivista e construtivista, a avaliação é entendida como parte integrante do processo de ensino e de aprendizagem e toma por objeto os processos de construção da aprendizagem pelos alunos, isto é, o funcionamento cognitivo deles na realização de tarefas de aprendizagem (SANTOS et al., 2010). Isto porque " a tarefa é antes de tudo uma 
situação de aprendizagem para o aluno e a avaliação está então integrada nessa situação" (LOPEZ, 2015, p. 63). Considera-se que só conhecendo os raciocínios feitos pelos alunos durante a realização de uma tarefa é que se pode compreender as causas das suas dificuldades e dos seus erros e, só assim, se pode intervir de forma adequada. Neste contexto, "avalia-se para se conhecer e só conhecendo o que o aluno sabe ou não sabe é que é possível realizar intervenções pedagógicas apropriadas, que tendam a gerar melhorias nas suas aprendizagens" (BOGGINO, 2009, p. 79). Logo, a avaliação é direcionada para a compreensão dos percursos de aprendizagem, com as dificuldades e os erros dos alunos, e para os fatores que estão na sua origem. Esta compreensão dos percursos de aprendizagem visa delinear uma intervenção pedagógica para a melhoria das aprendizagens, com superação das suas dificuldades e erros.

Assim a avaliação para a aprendizagem pressupõe que o professor, orientado por objetivos ou por critérios de avaliação das tarefas de aprendizagem, que têm de ser do conhecimento dos alunos, recolha e analise informações sobre os processos de aprendizagem, identificando as suas dificuldades e os seus erros, bem como o que os originou. A identificação e a exploração do erro com a participação do aluno são preponderantes numa avaliação para a aprendizagem, porque "o erro pode ser revelador da lógica associada à representação que o aluno faz de um certo saber" (SANTOS et al., 2010, p. 62). É através da exploração do erro que se torna possível "compreender de que modo o aluno está a pensar e como podemos ajudá-lo a reorientar o seu raciocínio ou a tomar consciência do seu conceito erróneo" (SANTOS, 2016, p. 646). Segundo Santos et al. (2010), o erro na aprendizagem deve ser entendido como uma dificuldade na construção/apropriação dos conceitos que estão a ser trabalhados. Logo, a sua análise permite ao professor aceder ao pensamento do aluno na apropriação desses conceitos, levando-o, através de um processo reflexivo e autoavaliativo, a verbalizar e a tomar consciência desse raciocínio que esteve na origem do erro ou da dificuldade. Desta forma, ambos podem negociar e corresponsabilizar-se pela implementação de uma medida pedagógica que permita a superação do erro ou da dificuldade, no intuito da realização de uma aprendizagem significativa. É neste sentido que Boggino (2009, p. 80) afirma que

ensinar implica, sempre, avaliar os saberes dos alunos e propor estratégias pertinentes, para que os alunos possam, progressivamente, ir reestruturando e ressignificando esquemas e conhecimentos e, assim, diminuir a distância que separa estes dos conteúdos curriculares. 
Neste contexto, a avaliação formativa concretiza-se na elaboração de diagnósticos contínuos (FERNANDES; ALVES; MACHADO, 2008), a partir dos quais é proporcionado aos alunos um feedback oral ou escrito sobre o que aprenderam, o que precisam melhorar ou alterar na sua aprendizagem, mas também indicando pistas que os ajudem a ultrapassar as suas dificuldades (BRUNO; SANTOS, 2010). Com esse feedback é possível a regulação do processo de ensino e de aprendizagem pelo professor com o aluno, isto é, a decisão e a implementação de uma intervenção pedagógica que se pretende adequada às necessidades individuais de cada aluno (FERREIRA, 2007; LOPEZ, 2015). Sendo a regulação entendida como "um processo deliberado e intencional que visa controlar os processos de aprendizagem, para que possa consolidar, desenvolver ou redirecionar essa aprendizagem" (FERNANDES, 2005, p. 67), é através dela que são utilizadas medidas de diferenciação pedagógica em função das diversas necessidades de aprendizagem. Esta diferenciação pedagógica consiste na tomada de decisões do professor, em negociação ou não com os seus alunos, sobre estratégias, atividades e recursos de ensino e de aprendizagem que permitam a superação das dificuldades diagnosticadas através da avaliação formativa, ou o aprofundamento das aprendizagens feitas (LOPEZ, 2015; PERRENOUD, 2004). Daí a avaliação formativa induzir "uma rutura ao propor deixar de lado o grau de regulação grupal e transferi-la para a individualização, em busca de uma intervenção adequada ao processo individual de cada aluno" (ZUNINO, 2016, p. 76). A finalidade desta intervenção diferenciada é, não só a superação de dificuldades e de erros, como também a realização de aprendizagens significativas pelos alunos (BOGGINO, 2009).

Só com uma avaliação contínua, reguladora e participada por ambos os intervenientes, se consegue "gerar alunos autónomos, capazes de fazer juízos críticos e de se governarem a si mesmos, em contraponto a alunos heterónomos que, por obediência ou 'respeito' aos docentes, apenas repetem os conteúdos sem os compreender" (BOGGINO, 2009, p. 83). Daí que, assumindo uma dimensão formativa e formadora do aluno, a avaliação seja uma prática realizada para a aprendizagem dos diversos alunos, na consideração pelas necessidades individuais que vão manifestando no decorrer dos seus processos de aprendizagem.

\section{Para uma prática da avaliação para a aprendizagem}

Enquanto processo realizado para promover a aprendizagem dos alunos, a prática da avaliação formativa pressupõe, segundo Santos et al. (2010), que 
esteja integrada no processo de ensino e de aprendizagem, que os objetivos de aprendizagem estejam clarificados para o professor e para o aluno, que incida privilegiadamente nos processos de aprendizagem e que propicie a compreensão e a reflexão desses mesmos processos.

Considerando esses pressupostos, para que seja desencadeada uma prática avaliativa com aquela finalidade é necessária a sua planificação, tomando-se, previamente ao ato avaliativo, decisões sobre os procedimentos e os instrumentos a serem nela utilizados (SANTOS, 2016). Após essa planificação, o professor, preferencialmente pela observação dos alunos durante a realização de tarefas (LOPEZ, 2015), recolhe as informações sobre as aprendizagens que estão a fazer e sobre as suas dificuldades ou erros. Mas, porque a "avaliação formativa terá obrigatoriamente que contar com uma intervenção ativa do aluno, quer total, quer parcial" (SANTOS, 2016, p. 640), também este, através da sua autoavaliação contínua, deve ser conduzido a refletir, de forma distanciada e crítica, sobre o processo de realização de cada tarefa de aprendizagem em que se encontra envolvido (VEIGA-SIMÃO, 2005). Nesta reflexão, quer seja realizada autonomamente pelo aluno, quer seja estimulada e orientada pelo professor,

o aluno é levado a explicitar as suas representações, a refletir sobre as suas estratégias, a confrontar os seus processos com os dos outros, a integrar os critérios externos nos seus quadros de referência, a gerar ativamente as relações entre as diferentes tarefas a cumprir. (ALLAL, 1999, p. 443-444).

Todas estas informações recolhidas pelo professor e/ou pelo aluno são analisadas pela comparação com os critérios de realização e de sucesso estabelecidos para a tarefa de aprendizagem e que são definidos em função do produto final esperado (SANTOS et al., 2010; VESLIN; VESLIN, 2001). Os critérios de realização, ou de procedimentos, indicam os passos ou os procedimentos a serem executados pelo aluno durante a realização de uma tarefa para que seja nela sucedida. Já os critérios de sucesso indicam as caraterísticas finais que uma tarefa tem que assumir depois de concluída (VESLIN; VESLIN, 2001). Esses critérios, que têm que ser comunicados ao aluno numa linguagem que lhes seja acessível para serem por ele interiorizados, constituem uma orientação para a sua aprendizagem e para a sua autoavaliação, já que lhe permitem planificar e controlar o processo de realização da tarefa de aprendizagem (ALLAL, 1999; FERREIRA, 2007). Mas também são a referência para a comparação das informações que o professor recolhe dos alunos sobre os seus percursos de aprendizagem. 
Deste modo, no processo de análise de informações, através do qual é realizado o diagnóstico das aprendizagens que estão a ser feitas, das dificuldades e dos erros, o professor estabelece um diálogo reflexivo com o aluno para compreender os raciocínios por ele elaborados e que originaram uma determinada dificuldade ou erro (SANTOS et al., 2010). Ao levar o aluno a verbalizar as representações que fez da tarefa em causa e os raciocínios feitos que o conduziram a esse erro ou dificuldade (ALLAL, 1986), o professor implica-o no processo avaliativo, porque leva-o a consciencializar-se da sua aprendizagem (ALLAL, 1999; SANTOS et al., 2010). Nessa perspetiva, "a avaliação formativa é sobretudo interativa, desenvolvendo-se a par e passo com as atividades de aprendizagem e a reflexão sobre essas, isto é, no quotidiano da sala de aula" (SANTOS, 2016, p. 641).

Sendo elaborado o diagnóstico da aprendizagem e, dessa forma, o juízo avaliativo, o professor proporciona o feedback aos alunos, que consiste em dar-lhes informações, em tempo útil, sobre "o seu rendimento que lhes permite apreciar as semelhanças e as diferenças entre os standards apropriados para o desempenho da tarefa e as qualidades do seu próprio [desempenho], podendo, assim, gerar uma série de melhorias no mesmo" (BOUD; MOLLOY, 2015, p. 20). Trata-se, por isso, de dar aos alunos as informações detalhadas e atempadas sobre as suas aprendizagens, sobre as suas dificuldades ou erros e sobre as suas causas, mas também dar pistas que os ajudem a ultrapassar as dificuldades ou melhorarem o que precisam (BRUNO; SANTOS, 2010). Para que este feedba$c k$ seja uma prática realizada para promover a aprendizagem, deve assumir as seguintes caraterísticas: deve incidir, de forma clara para o aluno, nos erros ou nas dificuldades diagnosticadas, bem como nas estratégias de aprendizagem por ele usadas e que o conduziram a esses erros ou dificuldades; tem de dar sugestões de como o aluno pode superar o erro ou a dificuldade por vias alternativas; deve estimular o pensamento do aluno, para que possa, de forma progressiva e autónoma, corrigir os seus erros ou superar as suas dificuldades; tem de focar-se mais no processo de aprendizagem que nos resultados; tem de ser implementado de forma sistemática e tem, também, de identificar as aprendizagens já feitas (BRUNO; SANTOS, 2010).

A partir deste feedback proporcionado, o professor pode negociar estratégias pedagógicas diferenciadas com o aluno com dificuldades, numa perspetiva de regulação interativa (ALLAL, 1986; FERNANDES; ALVES; MACHADO, 2008). Ainda o próprio aluno, caso tenha vontade e tenha desenvolvido competências metacognitivas que lhe permitam autoavaliar-se (VEIGA-SIMÃO; FRISON; MACHADO, 2015), pode, a partir da monitorização e do controle que exerce durante a realização de uma tarefa de aprendizagem, desencadear um processo de regulação interna ou de autorregulação (ALLAL, 2007). Esta autorregulação é entendida como 
um processo ativo em que os sujeitos estabelecem objetivos que nortearão a sua aprendizagem por meio do monitoramento, controle e regulação da cognição, da motivação e do comportamento com o intuito de alcançar esses objetivos (VEIGA-SIMÃO; FRISON; MACHADO, 2015, p. 34).

Pela monitorização e pelo controle exercido pelo aluno durante a resolução da tarefa (autoavaliação) que visa a realização da aprendizagem, é-lhe possível diagnosticar dificuldades, erros ou melhorias a fazer nessa tarefa. Em função deste diagnóstico, o próprio aluno decide os meios necessários para ultrapassar a sua dificuldade, ou pede a ajuda de que precisa ao professor ou a um colega. Neste caso, a autorregulação concretiza-se por uma regulação interativa, na medida em que "as regulações interativas da aprendizagem estavam definidas pelo facto que elas provêm das interações do aprendiz com os atores no seu meio (professor, outros alunos) e/ou com instrumentos que favoreçam processos autorreguladores" (ALLAL, 2007, p. 13).

Sendo realizada a avaliação reguladora da aprendizagem pelo professor, ou pelo próprio aluno, ou por ambos em conjunto, são criadas as condições pedagógicas necessárias e adequadas para que os alunos realizem aprendizagens significativas, propiciadoras do seu sucesso escolar, pelo que se torna numa prática avaliativa a implementar no quotidiano da sala de aula.

\section{A avaliação formativa no contexto normativo da avaliação das aprendizagens no ensino básico português}

Desde 2012, em Portugal, com a publicação do Decreto-Lei nº 139/2012, se assiste a orientações normativas para a avaliação das aprendizagens direcionadas para o reforço da avaliação sumativa externa com a introdução de exames nacionais a português e a matemática nos anos terminais dos três ciclos do ensino básico (FERREIRA, 2015). Porém, com uma nova governação que entrou em vigor no final de 2015, surgiu um novo regulamento de avaliação das aprendizagens dos alunos para o ensino básico, através da publicação do Despacho-Normativo $n^{\circ} 1-\mathrm{F} / 2016$, de 5 de abril. Este normativo retirou a ênfase dada no anterior à avaliação sumativa externa, acabando com os exames nacionais a português e a matemática nos $1^{\circ} \mathrm{e} 2^{\circ}$ ciclos do ensino básico e "afirmando a dimensão eminentemente formativa da avaliação, que se quer integrada e indutora de melhorias no ensino e na aprendizagem (PORTUGAL, 2016, 
preâmbulo). Passou a considerar que a avaliação da aprendizagem tem "como principal objetivo a melhoria da qualidade das aprendizagens" e a promoção do sucesso educativo dos alunos (PORTUGAL, 2016, preâmbulo).

Sendo a avaliação formativa considerada a principal modalidade de avaliação no ensino básico (PORTUGAL, 2016, art. 11), ela integra-se no processo de ensino e de aprendizagem e tem de ser realizada continuamente, de modo a cumprir as funções que tradicionalmente lhe estão associadas. Funções essas que são a de informação dos diferentes intervenientes sobre os processos de aprendizagem dos diversos alunos e a de regulação do ensino e da aprendizagem (FERNANDES; ALVES; MACHADO, 2008; FERREIRA, 2007). Nesse sentido, é referido no normativo que "a avaliação tem uma vertente contínua e sistemática e fornece ao professor, ao aluno, ao encarregado de educação e aos restantes intervenientes informação sobre o desenvolvimento do trabalho, de modo a permitir a revisão e a melhoria do processo de ensino e de aprendizagem" (PORTUGAL, 2016, art. $3^{\circ}$ ). Com a prática da avaliação formativa pretende-se o diagnóstico contínuo dos processos de aprendizagem, a intervenção com estratégias pedagógicas nas dificuldades detetadas e a fundamentação das opções pedagógicas e metodológicas de ensino realizadas pelo professor, de forma a criar as condições necessárias para que o maior número possível de alunos tenha sucesso escolar. Esta prática de avaliação formativa é realizada a partir de critérios de avaliação aprovados em conselho pedagógico da escola e delimitados em função das orientações curriculares definidas pelo Ministério da Educação (objetivos, conteúdos programáticos e metas curriculares definidas oficialmente para as disciplinas). Estes critérios são operacionalizados por cada professor (PORTUGAL, 2016, art. $7^{\circ}$ ). Com estes critérios de avaliação pretende-se a delimitação do perfil de aprendizagens específicas para cada ano de escolaridade ou ciclo (PORTUGAL, 2016, art. $7^{\circ}$ ). Na operacionalização dos critérios, e no âmbito da prática da avaliação formativa, o professor vai delimitar os critérios de realização e de sucesso (VESLIN; VESLIN, 2001), que o vão orientar na recolha e na análise de informações sobre os processos de aprendizagem.

Em função dos critérios de avaliação delimitados, a prática da avaliação formativa deve ser realizada privilegiando os seguintes procedimentos:

a) A regulação do ensino e das aprendizagens, através da recolha de informação que permita conhecer a forma como se ensina e como se aprende, fundamentando a adoção e o ajustamento de medidas e estratégias pedagógicas;

b) O caráter contínuo e sistemático dos processos avaliativos e sua adaptação aos contextos em que ocorrem; 
c) A diversidade das formas de recolha de informação, através da utilização de diferentes técnicas e instrumentos de avaliação, adequando-os às finalidades que lhes presidem. (PORTUGAL, 2016, art. 11).

Sendo realizada para promover as aprendizagens e orientada por critérios de avaliação que têm que ser conhecidos pelos diversos intervenientes no processo educativo (PORTUGAL, 2016, art. $7^{\circ}$, ponto 4), a recolha de informações sobre os percursos de aprendizagem deve ser feita com o recurso a instrumentos de avaliação diversificados, em função do objeto de avaliação a que servem. Porque através da prática dessa avaliação se procura a elaboração de um diagnóstico contínuo dos processos de aprendizagem, com a identificação das aprendizagens que os alunos estão a fazer, das suas dificuldades e erros e respetivas causas, o professor não poderá usar unicamente os testes escritos como fonte de recolha de informações, já que eles só proporcionam informações sobre resultados de aprendizagem do domínio cognitivo (FERREIRA, 2007; PASTOR, 2011). Para a obtenção dessas informações, o professor tem de recorrer à observação instrumentada, aos diálogos reflexivos com os alunos, através dos quais verifica a forma como estão a realizar a tarefa, as representações e os raciocínios por eles elaborados (PASTOR, 2011). Assim é possível a deteção das dificuldades de aprendizagem no momento em que surgem e a compreensão das causas dessas dificuldades ou erros (FERREIRA, 2007). A análise das informações recolhidas, feita pela comparação com os critérios de avaliação delimitados para cada tarefa de aprendizagem, leva o professor a decidir, ou a negociar com cada aluno com dificuldades, uma estratégia de regulação do seu processo de aprendizagem, cuja implementação visa fazer com que as dificuldades sejam ultrapassadas e seja conseguido o sucesso escolar.

\section{Metodologia de investigação sobre as percepções de estagiários sobre as suas práticas de avaliação das aprendizagens}

\section{Problema e objetivos de investigação}

Com a implementação do novo sistema de avaliação das aprendizagens no ensino básico português (PORTUGAL, 2016), a prática da avaliação formativa que promove as aprendizagens nos alunos assumiu outra relevância. Deste modo, foi nossa intenção aceder às percepções de estagiários do $1^{\circ}$ ciclo do ensino básico sobre as práticas de avaliação por eles realizadas no estágio desse ciclo, 
isto é, na prática de ensino supervisionada pelo orientador da Universidade e pelo professor titular da turma que foi realizada por cada um deles numa turma desse ciclo do ensino básico. Dessa forma, o problema de investigação que originou o presente estudo foi delimitado na seguinte questão: quais as percepções dos estagiários do $1^{\circ}$ ciclo do ensino básico da Universidade de Trás-os-Montes e Alto Douro sobre as suas práticas de avaliação das aprendizagens no estágio nesse ciclo de ensino no que respeita: à concepção de avaliação das aprendizagens que os orientou; à prática da avaliação formativa por eles realizada; ao feedback proporcionado aos alunos; às estratégias de regulação das aprendizagens por eles implementadas.

Com esse problema de investigação, definimos como objetivos do estudo os seguintes: compreender as concepções dos estagiários do $1^{\circ}$ ciclo do ensino básico sobre o conceito de avaliação das aprendizagens que os orientou na realização da avaliação dos alunos da turma de estágio; verificar as suas percepções sobre as práticas de avaliação formativa que realizaram no contexto do estágio; identificar as suas percepções sobre ofeedback que proporcionaram aos alunos da turma onde realizaram o estágio; compreender as suas percepções sobre as estratégias pedagógicas de regulação das aprendizagens que foram por eles utilizadas no estágio no $1^{\circ}$ ciclo do ensino básico.

\section{Procedimentos de recolha e de análise de dados}

Tendo procurado aceder e compreender as percepções de estagiários do $1^{\circ}$ ciclo do ensino básico da Universidade de Trás-os-Montes e Alto Douro sobre as suas práticas de avaliação das aprendizagens realizadas no âmbito do seu estágio no referido ciclo de ensino, pareceu-nos adequada a utilização de uma metodologia de investigação qualitativa (BOGDAN; BIKLEN, 1994), concretizada por um estudo exploratório de caso (YIN, 2005). Para "analisar, descrever e compreender" (MORGADO, 2012, p. 56) as percepções dos referidos estagiários sobre as suas práticas de avaliação das aprendizagens, pareceu-nos adequada a elaboração e a aplicação de um questionário com questões abertas. Pois, segundo Morgado (2012, p. 77),

um questionário é uma série ordenada e coerente de perguntas que são colocadas a um conjunto de inquiridos para colher elementos [...] sobre as suas opiniões, as atitudes que assumem e/ou a forma como se posicionam perante certas questões humanas e sociais, acontecimentos ou problemas, as suas expectativas, o seu nível de conhecimentos e, ainda, sobre qualquer temática ou assunto de interesse para o investigador. 
Para além das questões de caraterização pessoal dos inquiridos referentes à idade e ao curso que frequentavam, o dito questionário foi composto por sete questões abertas com as quais se procurou aceder às percepções dos estagiários sobre: as suas concepções de avaliação das aprendizagens que os orientou no estágio no $1^{\circ}$ ciclo do ensino básico; as finalidades da avaliação das aprendizagens que realizaram; as técnicas e instrumentos de avaliação que foram por eles usados; of feedback dado aos alunos das suas turmas de estágio; as estratégias de regulação das aprendizagens utilizadas. Antes de ser administrado, o questionário foi validado por "acordo de juízes" (FOX, 1987), isto é, foi analisado por dois investigadores da área de avaliação das aprendizagens e por um da metodologia de investigação em educação para darem a sua opinião sobre a pertinência, a clareza e a abrangência das questões face ao problema e aos objetivos da investigação. Da análise feita pelos juízes não resultaram quaisquer alterações à versão inicial do questionário, pois consideraram as questões claras, pertinentes e abrangentes face ao objeto de estudo.

Assim o questionário foi administrado no final do estágio do $1^{\circ}$ ciclo do ensino básico do ano letivo 2016/2017 à totalidade (28) dos estagiários dos três cursos da Universidade de Trás-os-Montes e Alto Douro de formação inicial de professores para esse nível de ensino: Mestrado em Educação Pré-Escolar e Ensino do $1^{\circ}$ Ciclo do Ensino Básico (20 estgiários); Mestrado em Ensino do $1^{\circ}$ Ciclo do Ensino Básico e de Português e História e Geografia de Portugal no $2^{\circ}$ Ciclo do Ensino Básico (4 estagiários); Mestrado em Ensino do $1^{\circ}$ Ciclo do Ensino Básico e de Matemática e Ciências Naturais do $2^{\circ}$ Ciclo do Ensino Básico (4 estagiários).

Os dados recolhidos através do questionário foram submetidos à análise de conteúdo, da qual resultou uma categorização emergente (BARDIN, 1995). Dessa análise emergiram as seguintes categorias e subcategorias: 1) conceito de avaliação da aprendizagem; 2) finalidade da avaliação da aprendizagem, com as subcategorias diagnóstico e regulação da aprendizagem, consolidação das aprendizagens; 3 ) momentos da avaliação, com as subcategorias ao longo da aula, final da aula, avaliação diagnóstica; 4) técnicas e instrumentos de avaliação; 5) razões da opção pelos instrumentos de avaliação usados, com as subcategorias diagnóstico das aprendizagens, facilidade na avaliação, regulação da aprendizagem; 6) o feedback aos alunos; 7) estratégias de regulação da aprendizagem; 8) autoavaliação dos alunos. 


\section{As percepções dos estagiários sobre as suas práticas de avaliação das aprendizagens}

Os resultados da análise de conteúdo às respostas escritas dos estagiários do $1^{\circ}$ ciclo do ensino básico da Universidade de Trás-os-Montes e Alto Douro, do ano letivo 2016/2017, às questões abertas que compunham o questionário são, de seguida, apresentados pelas categorias identificadas.

\section{Conceito de avaliação das aprendizagens}

O conceito de avaliação das aprendizagens, apesar de polissémico, é atualmente perspetivado como um processo integrado no ensino e na aprendizagem conducente a uma valoração traduzida de diferentes formas, consoante a finalidade da mesma (FERREIRA, 2007; NEVES; FERREIRA, 2015). A percepção que a maioria dos estagiários do $1^{\circ}$ ciclo do ensino básico evidenciou sobre o conceito de avaliação das aprendizagens assumiu uma dimensão formativa, cuja relevância deste tipo de avaliação é destacada no preâmbulo e no artigo $11^{\circ}$ do Despacho-Normativo $\mathrm{n}^{\circ} 1-\mathrm{F} / 2016$. Consideraram tratar-se de um processo integrado no ensino e na aprendizagem e que é realizado para a elaboração de diagnósticos contínuos das aprendizagens feitas e das dificuldades dos alunos das suas turmas de estágio. A elaboração deste diagnóstico visava, segundo os estagiários, a intervenção pedagógica nas dificuldades detetadas (FERREIRA, 2007; NEVES; FERREIRA, 2015; SANTOS, 2016). Os discursos que a seguir se transcrevem são exemplificativos deste conceito de avaliação da aprendizagem numa lógica formativa:

Percebi que temos que ter muitos momentos de avaliação e variados, uma vez que assim podemos ajudar os alunos a ultrapassarem as suas dificuldades (Estagiário J).

A avaliação das aprendizagens permite ao professor perceber se os alunos têm dificuldades em certos conteúdos, o que permite também ajustar as técnicas pedagógicas (Estagiário X).

Já alguns estagiários evidenciaram percepções de avaliação formativa pontual, numa perspetiva de verificação de resultados de aprendizagem, ou do 
cumprimento dos objetivos traçados no final do processo de ensino e de aprendizagem (ALLAL, 1986). Para isso, na sua prática eram utilizadas fichas formativas e até mesmo somativas, como podemos ver nos discursos que se seguem:

A avaliação das aprendizagens que os professores do $1^{\circ}$ ciclo do ensino básico executam é muito na base de fichas formativas e somativas (Estagiário B).

O meu entendimento sobre a avaliação das aprendizagens é que é feita através de fichas de avaliação (Estagiário $\mathrm{O}$ ).

Avaliar é um processo que exige planificação, a recolha e análise de informações e a tomada de decisões pedagógicas que promovam a aprendizagem dos alunos.

\section{Finalidades da avaliação das aprendizagens}

Assumindo uma dimensão formativa, o conceito de avaliação das aprendizagens dos estagiários e as percepções da maioria deles sobre a finalidade dessa avaliação foram a de diagnóstico e de regulação das aprendizagens dos alunos, tal como também se encontra previsto no preâmbulo do Despacho-Normativo $\mathrm{n}^{\circ} 1-\mathrm{F} / 2016$. Os discursos que se seguem são exemplificativos:

A finalidade dessa avaliação era aferir os conteúdos em que os alunos tinham mais dificuldades e os conteúdos em que tinham menos dificuldades, de forma a tentar colmatar as dificuldades, para que consigam progredir nos conteúdos sem terem dificuldades (Estagiário B).

Tem como finalidade perceber os erros/dificuldades dos alunos e perceber qual o motivo desses erros/ dificuldades, ou seja, detetar os processos cognitivos dos alunos em determinada tarefa e perceber o motivo da dificuldade (Estagiário U).

Percebe-se, pelos seus discursos, que os estagiários realizaram a avaliação das aprendizagens com a finalidade da elaboração de um diagnóstico atempado 
das dificuldades e dos erros dos alunos e dos raciocínios por eles feitos e que originaram essas dificuldades e erros (LOPEZ, 2015; SANTOS et al., 2010). Conhecendo as dificuldades e as suas causas, o professor encontra-se em condições para regular o processo de ensino e de aprendizagem, através da intervenção com estratégias de ensino diferenciadas (PERRENOUD, 2004) que permitam aos alunos ultrapassá-las.

Porém, alguns estagiários mencionaram que a avaliação das aprendizagens tinha por finalidade a repetição, ou a "consolidação" dos conteúdos aprendidos, numa lógica de regulação retroativa (ALLAL, 1986). Este tipo de regulação, de influência behaviorista, consiste no retorno da informação que os alunos não conseguiram aprender (ALLAL, 2007). Para isso, o professor sugere ao aluno o estudo suplementar no manual escolar dos conteúdos não aprendidos, ou propõe situações de treino e de reforço das aprendizagens feitas pela realização de mais exercícios para a pretendida consolidação das aprendizagens (FERREIRA, 2007). Tal finalidade da avaliação pode ser observada nos discursos que se seguem:

[A avaliação das aprendizagens] tinha como objetivo de consolidação de conhecimentos e para que os alunos recapitulassem os conteúdos (Estagiário R).

Esta avaliação tinha como objetivo consolidar os conteúdos abordados (Estagiário V).

\section{Momentos da realização da avaliação das aprendizagens}

Tendo as suas práticas de avaliação das aprendizagens intencionalidades distintas, os estagiários percepcionaram diferentes momentos da sua realização. Assim alguns afirmaram ter feito a avaliação diagnóstica, no início das aulas, ou de um novo conteúdo, para verificarem os conhecimentos prévios ou os pré-requisitos dos alunos para a aprendizagem dos novos conteúdos que iam ensinar (FERREIRA, 2007):

No início das aulas, com o questionamento oral aos alunos. A finalidade era ter uma percepção dos conhecimentos prévios dos alunos (Estagiário T). 
No início de um novo conteúdo para fazer a diagnose dos conhecimentos prévios e dos pré-requisitos (Estagiário $\mathrm{X}$ ).

Por outro lado, a avaliação formativa contínua é realizada por observação instrumentada dos alunos durante as tarefas de aprendizagem, permitindo o diagnóstico das suas dificuldades e erros no momento em que surgiam e dos raciocínios por eles feitos e que os originaram (ALLAL, 1986; FERNANDES; ALVES; MACHADO, 2008; SANTOS et al., 2010). Neste sentido, a maioria dos estagiários percepcionou ter feito a avaliação formativa das aprendizagens durante a realização das tarefas que propunham aos alunos nas suas aulas, como se pode ver, por exemplo, nos discursos seguintes:

Realizei a avaliação durante o desenvolvimento das tarefas propostas aos alunos (Estagiário U).

A avaliação decorre em vários momentos. Desta forma, os alunos são monitorizados no seu processo de aprendizagem, chegando mais facilmente ao sucesso (Estagiário AE).

A avaliação dos processos de aprendizagem, através da observação planeada e estruturada por critérios e por instrumentos de avaliação dos alunos durante a realização de tarefas de aprendizagem, permite "a recolha de evidências das aprendizagens e garante a qualidade e correção das avaliações desde que ocorra com frequência e em contextos diversificados" (NEVES; FERREIRA, 2015, p. 73). Deste modo, os estagiários afirmaram fazer essa observação durante as tarefas de aprendizagem. Já os restantes estagiários referiram ter realizado uma prática de avaliação formativa no final de cada aula, tendo por finalidade a consolidação das aprendizagens feitas pelos alunos e, dessa forma, a verificação do cumprimento pelos alunos dos objetivos estipulados para as aulas. Esta prática concretiza-se, usualmente, pela resolução de fichas formativas e por exercícios escritos após os conteúdos terem sido ensinados (FERREIRA, 2007) como podemos verificar nos discursos que se transcrevem:

A avaliação era normalmente realizada após a lecionação do conteúdo através de fichas formativas (Estagiário C). 
No final da aula, através de fichas formativas, para verificar se os conteúdos foram interiorizados (Estagiário N).

\section{Técnicas e instrumentos de avaliação das aprendizagens}

Tendo sido assumido pelos estagiários o diagnóstico dos processos de aprendizagem ou a consolidação das aprendizagens feitas como finalidades das suas práticas de avaliação, afirmaram usar o questionamento oral aos alunos durante a lecionação dos conteúdos, instrumentos de observação na realização de tarefas de aprendizagem e as fichas formativas atribuídas após o ensino dos conteúdos:

A técnica mais frequente foi o questionamento oral seguido de fichas formativas (Estagiário A).

Utilizei listas de verificação e grelhas de observação (Estagiário I).

No estágio utilizei duas listas de verificação, uma para a escrita de um texto, para verificar a forma como escreviam e a outra para o trabalho em grupo, para verificar os comportamentos e se já tinham desenvolvido a capacidade de trabalhar com os colegas (Estagiário S).

As técnicas utilizadas foram a observação e as fichas formativas, sendo que na observação utilizei como instrumentos de observação a lista de verificação e a grelha de observação (Estagiário U).

Pela utilização de instrumentos diversificados, tal como é sugerido pelo artigo $11^{\circ}$ do Despacho-Normativo $\mathrm{n}^{\circ} 1-\mathrm{F} / 2016$, nomeadamente do questionamento oral dos alunos durante o ensino dos conteúdos e da observação instrumentada com listas de verificação e com grelhas de observação, ao que Lopez (2015) designa de avaliação formativa instrumentada, os estagiários afirmaram ter avaliado os processos de aprendizagem e ter diagnosticado atempadamente as dificuldades que surgiam. Caso a verificação das dificuldades pela observação dos alunos tenha sido articulada com o diálogo reflexivo sobre os raciocínios 
por eles efetuados (SANTOS et al., 2010), a avaliação realizada terá permitido a compreensão das causas dessas dificuldades (ALLAL, 1986; FERNANDES; ALVES; MACHADO, 2008). Por outro lado, a utilização das fichas formativas após a lecionação dos conteúdos possibilitou aos estagiários avaliarem os resultados de aprendizagem e, dessa forma, verificarem o cumprimento, pelos alunos, dos objetivos de aprendizagem definidos para as aulas (ALLAL, 1986).

\section{Razões da opção pelos instrumentos de avaliação usados}

Os estagiários afirmaram ter optado pelos instrumentos de avaliação indicados anteriormente por lhes permitirem diagnosticar as aprendizagens, as dificuldades e os erros dos alunos, mas também pela facilidade na sua utilização, como podemos ver nas transcrições que se seguem:

Optei pelas fichas formativas porque é um instrumento completo e importante, que me permite perceber as dificuldades dos alunos e colmatá-las (Estagiário B).

As listas de verificação, optei pela facilidade, pois através do "sim", "não" e "tem dificuldades", foi mais fácil avaliar os alunos nos itens a observar (Estagiário F).

Optei pelas listas de verificação para perceber em que aspetos os alunos tinham mais dificuldades, para orientar o meu planeamento de próximas aulas, no sentido de melhorar essas dificuldades (Estagiário V).

Porque é mais fácil conseguir avaliar a evolução dos alunos (Estagiário Q).

Ainda outros estagiários referiram que a utilização dos instrumentos de observação e das fichas formativas lhes permitiu a regulação das aprendizagens dos alunos: 
Optei por estas técnicas e instrumentos porque me permitia, atempadamente, uma adaptação das estratégias de ensino de acordo com as dificuldades dos alunos no momento das dificuldades (Estagiário U).

Assim [com os instrumentos de observação] podia estar mais presente para tirar dúvidas ou corrigir erros ou ajudá-los a superar dificuldades (Estagiário Z).

\section{O feedback aos alunos}

Tendo sido proporcionadas informações sobre os processos e sobre os resultados de aprendizagem pela prática da avaliação formativa, os estagiários afirmaram ter proporcionado feedback aos alunos. Sendo o feedback constituído pelas informações que o professor dá aos alunos, em tempo útil, sobre as aprendizagens feitas, sobre as suas dificuldades e sobre como as podem melhorar ou corrigir (BRUNO; SANTOS, 2010), os estagiários afirmaram ter dado feedback oral no decorrer das tarefas de aprendizagem e também escrito, aquando da correção das fichas formativas resolvidas:

Ao longo de todo o processo foi dado feedback, quer escrito, quer oral, sendo o mais frequente o feedback oral (Estagiário A).

Dei feedback oral aos alunos no decorrer da lecionação dos diferentes conteúdos e da resolução de exercícios (Estagiário G).

Dei feedback escrito através da correção das fichas formativas (Estagiário Z).

Como sugerem Bruno e Santos (2010) e Boud e Molloy (2015), as informações proporcionadas pelos estagiários nesse feedback incluíam a valorização das aprendizagens feitas com vista à motivação dos alunos, a informação das dificuldades diagnosticadas e as sugestões para as superarem, como podemos observar nos seguintes discursos exemplificativos: 
Aliado a este feedback foi sempre dado elogio para os alunos se sentirem motivados. Penso que o feedback dado não se centrava só nos erros que o aluno dava, mas também no processo de pensamento que foi utilizado. Ia dando pistas para que o aluno conseguisse atingir o objetivo pretendido (Estagiário A).

Fui dizendo aos alunos as dificuldades que notava neles e o que podiam melhorar (Estagiário J).

À medida que os alunos tinham dificuldades, dava pistas para eles conseguirem chegar aos objetivos, assim como elogiá-los quando conseguiam os objetivos (Estagiário M).

\section{Estratégias de regulação da aprendizagem}

Com o juízo avaliativo formulado e com o feedback proporcionado, os estagiários desencadearam estratégias de regulação das aprendizagens, sobretudo naqueles alunos em que diagnosticaram dificuldades. A regulação das aprendizagens é um dos procedimentos previstos para a prática da avaliação formativa no Despacho-Normativo $\mathrm{n}^{\mathrm{o}} 1-\mathrm{F} / 2016$ e foi uma das finalidades apontadas pelos estagiários para as suas práticas avaliativas. Deste modo, alguns referiram ter implementado estratégias de regulação interactivas, isto é, de interação do aluno com o professor, com os colegas ou com outros recursos que lhes permitissem superar as suas dificuldades (ALLAL, 2007):

Para combater dificuldades, colocava um aluno que tivesse entendido bem a matéria a explicar para a restante turma (Estagiário C).

Comecei a recorrer ao trabalho cooperativo. Assim, estes tiveram que aprender a trabalhar com os outros e até a respeitar-se (Estagiário D).

As estratégias utilizadas foram a realização de atividades que os alunos não estavam habituados a fazer, como o trabalho de grupo e jogos (Estagiário O). 
Mas as estratégias de ensino mais referidas pelos estagiários foram as de regulação retroativa, como sejam a repetição pelo professor dos conteúdos não aprendidos, o estudo suplementar do aluno no manual escolar, a resolução de exercícios mais simples até conseguirem resolver aqueles em que foram evidenciadas dificuldades (ALLAL, 2007; FERREIRA, 2007), como podemos ver nos seguintes registos:

A repetição dos conteúdos, a apresentação de exercícios mais fáceis para assim poderem chegar à resolução de exercícios mais complicados em que tinham dificuldades (Estagiário G).

Repetição dos conteúdos nos quais os alunos sentiram dificuldades e fichas de trabalho com diversos exercícios sobre o conteúdo em questão (Estagiário $\mathrm{H}$ ).

Explorei melhor o tema até eles não sentirem dificuldades (Estagiário N).

Pedi aos alunos para fazerem a leitura do manual (Estagiário AF).

\section{Autoavaliação dos alunos}

Foram poucos os estagiários que mencionaram ter estimulado a prática da autoavaliação dos alunos. Aqueles que o fizeram, referiram ter-lhes solicitado, no final da aula, que refletissem sobre o que aprenderam e sobre os conteúdos ou exercícios em que precisavam de ajuda, em função dos objetivos das aulas que eram do seu conhecimento:

Os alunos, em todas as aulas, recebiam os objetivos de aprendizagem. Então, no fim dos conteúdos, tinham que assinalar como é que se sentiam em relação aos conteúdos abordados. Tinham que assinalar se já sabiam ou se precisavam de ajuda. Desta forma estavam a fazer a sua autoavaliação (Estagiário A).

No fim dos trabalhos em grupo, fizeram sempre o balanço de como correu e como o trabalho evoluiu (Estagiário $\mathrm{S}$ ). 
Tratou-se, por isso, de uma prática de autoavaliação pouco estruturada e pouco sistemática, na medida em que, para a fazer, os alunos teriam que ter interiorizado os critérios de avaliação das tarefas de aprendizagem e com eles refletiam, de forma distanciada e crítica, sobre a forma como estavam a realizar essas tarefas (VEIGA-SIMÃO, 2005). Só com uma autoavaliação contínua e centrada no processo de realização de tarefas os alunos poderiam, de forma autónoma e responsável, autorregular a sua aprendizagem.

\section{Considerações finais}

É inegável que a avaliação das aprendizagens pode ser realizada com diversas finalidades e funções pedagógicas, mas cada vez mais é destacada a sua função formativa, cuja prática é desencadeada para promover as aprendizagens nos alunos.

Orientando-nos por esta ideia, o estudo realizado sobre as percepções dos estagiários sobre as suas práticas de avaliação das aprendizagens permitiu-nos verificar que a sua percepção do conceito de avaliação das aprendizagens assumia uma dimensão formativa. A maioria deles referiu que se tratava de um processo realizado para diagnosticar as aprendizagens e as dificuldades dos alunos e a intervenção pedagógica nas mesmas. Ainda foi possível verificar que, realizando essa avaliação durante e no final da lecionação dos conteúdos, recolheram informações sobre os processos de aprendizagem. Esta recolha foi feita através do questionamento oral e de instrumentos de observação dos alunos durante a realização das tarefas escolares. Ainda procuraram recolher informações sobre os resultados de aprendizagem através de fichas formativas. Da análise das informações recolhidas, os estagiários referiram elaborar diagnósticos a que os alunos tinham acesso através do feedback oral, mas também do escrito. Para levarem os alunos a ultrapassarem as suas dificuldades, afirmaram ter usado estratégias de regulação retroativa e interativa, como a repetição pelo professor ou por um colega sem dificuldades dos conteúdos não aprendidos, a utilização de recursos didáticos diferenciados e a realização de exercícios e de fichas de trabalho. Ainda foi possível verificar que poucos foram aqueles que mencionaram ter estimulado a autoavaliação dos alunos, apesar de pouco sistemática e estruturada.

Deste modo, as percepções acedidas através deste estudo permitem-nos afirmar a necessidade de aprofundar a orientação dos estagiários para a realização de práticas de avaliação formativa contínuas, com critérios de avaliação das tarefas de aprendizagem devidamente clarificados para o professor e para os 
alunos, o que possibilitaria, também, uma prática de autoavaliação e de autorregulação das aprendizagens pelos alunos. Ainda seria necessária a utilização das estratégias de regulação interativas de forma mais consistente para enfrentarem as dificuldades de aprendizagem dos alunos, porque lhes permitiriam, com maior eficácia, a realização de aprendizagens significativas.

\section{REFERÊNCIAS}

ALLAL, L. Estratégias de Avaliação Formativa: concepções psicopedagógicas e modalidades de aplicação. In: ALLAL, L.; CARDINET, J.; PERRENOUD, P. A Avaliação Formativa num ensino diferenciado. Coimbra: Livraria Almedina, 1986. p. 175-209.

ALLAL, L. Impliquer l'apprenant dans le processus d'évaluation: promesses et pièges de l'autoévaluation. In: DEPOVER, C.; NÖEL, B. (Eds.). L'évaluation des compétences et des processus cognitifs. Modèles, pratiques et contexts. Bruxelles: De Boeck Université, 1999. p. 35-56.

ALLAL, L. Régulations des apprentissages: orientations conceptuelles pour la recherche et la pratique en éducation. In: ALLAL, L.; LOPEZ, L. M. (Dir.). Régulation des apprentissages en situation scolaire et en formation. Bruxelles: De Boeck Université, 2007. p. 7-23.

BARDIN, L. Análise de conteúdo. Lisboa: Edições 70, 1995.

BOGDAN, R.; BIKLEN, S. Investigação Qualitativa em Educação. Porto: Porto Editora, 1994.

BOGGINO, N. A avaliação como estratégia de ensino. Avaliar processos e resultados. Sisifo. Revista de Ciências da Educação, n. 9, p. 79-86, 2009.

BOUD, D.; MOLLOY, E. El Feedback en Educación Superior y Profesional. Comprenderlo y hacerlo bien. Madrid: Narcea Ediciones, 2015.

BRUNO, I.; SANTOS, L. Evolução da escrita avaliativa num contexto de trabalho colaborativo. Revista de Educação, v. XVII, n. 2, p. 61-92, 2010.

FERNANDES, D. Avaliação das aprendizagens: desafios às teorias, práticas e políticas. Lisboa: Texto Editores, 2005.

FERNANDES, J. A.; ALVES, M. P.; MACHADO, E. A. Perspectivas e práticas de avaliação de professores de Matemática. Braga: Centro de Investigação em Educação-Universidade do Minho, 2008.

FERREIRA, C. A. A Avaliação no quotidiano da sala de aula. Porto: Porto Editora, 2007.

FERREIRA, C. A. A avaliação das aprendizagens no ensino básico português e o reforço da avaliação sumativa externa. Educação e Pesquisa, v. 41, n. 1, p. 153-169, 2015. 
FOX, D. El proceso de investigación en educación. Pamplona: EUNSA, 1987.

LOPEZ, L. M. Évaluations Formative et Certificative des Apprentissages. Bruxelles: De Boeck Université, 2015.

MORGADO, J. C. O estudo de caso na investigação em Educação. Santo Tirso: De Facto Editores, 2012.

NEVES, A. C.; FERREIRA, A. L. Avaliar é Preciso? Guia Prático de Avaliação para Professores e Formadores. Lisboa: Guerra e Paz, 2015.

PASTOR, V. M. L. Evaluación Formativa y Compartida en Educación Superior. Propuestas, técnicas, instrumentos y experiencias. Madrid: Narcea Ediciones, 2011.

PERRENOUD, P. Pédagogie différenciée. Des intentions à l'action. 3. ed. Paris: ESF, 2004. PORTUGAL. Ministério da Educação e Ciência. Decreto-Lei n ${ }^{\circ}$ 139/2012, de 5 de julho. Revisão da estrutura curricular dos ensinos básico e secundário portugueses. Lisboa, 2012.

PORTUGAL. Ministério da Educação. Despacho-Normativo no 1-F/2016, de 5 de abril. Regime de avaliação das aprendizagens no ensino básico português. Lisboa, 2016.

SANTOS, L. A articulação entre a avaliação somativa e a formativa, na prática pedagógica: uma impossibilidade ou um desafio? Ensaio: Avaliação de Políticas Públicas em Educação, v. 24, n. 92, p. 637-669, 2016.

SANTOS, L. et al. Avaliar para Aprender. Relatos de experiências de sala de aula do pré-escolar ao ensino secundário. Porto: Porto Editora, 2010.

VEIGA-SIMÃO, A. M. Reforçar o valor regulador, formativo e formador da avaliação das aprendizagens. Revista de Estudos Curriculares, n. 2, p. 265-289, 2005.

VEIGA-SIMÃO, A. M.; FRISON, L. M. B.; MACHADO, R. F. Escrita de Resumos e Estratégias de Autorregulação da Aprendizagem. Cadernos de Pesquisa, v. 45, n. 155, p. 30-55, 2015.

YIN, R. K. Estudo de Caso. Planejamento e Métodos. 3. ed. Porto Alegre: Artmed Editora, 2005.

VESLIN, O.; VESLIN, J. Évaluation formatrice et criteres de realisation. In: FIGARI, G.; ACHOUCHE, M. L'activité evaluative réinterrogée. Regards scolaires et socioprofessionnels. Bruxelles: De Boeck Université, 2001. p. 89-101.

ZUNINO, C. C. Una Noción de Evaluación: La Evaluación Formativa en el Marco de las Concepciones de Finlandia y la Ciudad de Buenos Aires. Revista Iberoamericana de Evaluación Educativa, v. 9, n. 1, p. 75-90, 2016.

Texto recebido em 24 de janeiro de 2018. Texto aprovado em 12 de fevereiro de 2018. 